\title{
Scaffolding Progressive Online Discourse for Literary Knowledge Building
}

\author{
Marc Nachowitz \\ Miami University, Oxford, $\mathrm{OH}$
}

\begin{abstract}
Drawing on research from online, knowledge-building, and discussion-based learning, this designbased experiment captures the instructional moves theorized to develop student capacity in progressive, literary discourse. The experiment employed Knowledge Forum and its unique capacity to scaffold student learning of progressive discourse that results in an explanatory model, theory, or literary interpretation. Analysis of student discussion posts within and between two iterative phases suggest that explicit instruction in progressive discourse, combined with regular classroom debriefings of online discussion, contributed to student mastery. Additionally, the use of sentence starters aligned with each Knowledge Forum scaffold for progressive discourse provided positive outcomes. Implications for using online, progressive, literary discourse scaffolds to inculcate disciplinary thinking and discussion appropriate to the secondary English/Language Arts class are discussed.
\end{abstract}

Keywords: online discussion, literature discussion, design-based experiment, progressive discourse

Nachowitz, M. (2018). Scaffolding progressive online discourse for literary knowledge building. Online Learning, 22(3), 133-156. doi:10.24059/olj.v22i3.1261

\section{Scaffolding Progressive Online Discourse for Literary Knowledge Building}

Teaching online discourse around English/Language Arts (ELA) content is a twofold challenge. First, our nation's schools are failing to create highly literate, college- and career-ready adults with the literacy skills that qualify them for employment in the new, global knowledge economy (Carnegie Council on Advancing Adolescent Literacy, 2010). Consequently, calls for research investigating the kinds of literate acts 21 st-century readers and thinkers need must encompass skills in thinking creatively, effectively communicating and collaborating with teams of people, and making innovative use of knowledge and information (Partnership for 21st Century Skills, 2008). Second, a body of research within the literacy education community has established positive correlations between discussion-based approaches to the teaching of literature and student understanding (Applebee, Langer, Nystrand, \& Gamoran, 2003; Nystrand, 2006) justifying the creation and adaptation of an ELA Common Core Anchor Standard (CCSS) in speaking and 
listening. Specifically, the standard calls for students who can "initiate and participate effectively in a range of collaborative discussions . . . building on others' ideas and expressing their own clearly and persuasively ... propel conversations by posing and responding to questions; and clarify, verify, or challenge ideas and conclusions" (Common Core State Standards Initiative, 2010). In short, the challenge for ELA educators and researchers is to establish valid practices for scaffolding students' abilities to collaboratively construct knowledge through discussion and to prepare them to communicate and collaborate using 21 st-century tools. However, there is a dearth of research investigating how these challenges might be met together. What is lacking, and what the present study addresses, is research investigating how instructional activities designed to develop 21st-century literacy skills might be integrated into conventional ELA instruction (Howell, Butler, \& Reinking, 2017).

The author conducted a formative experiment with the goal of developing middle school students' abilities to collaboratively direct and sustain effective discussions around literature content using online tools. Formative, design-based research seeks to understand and document how and why a designed intervention works in practice (Ford, McNally, \& Ford, 2017). The present study sought pedagogical insight from employing digital discussion tools to scaffold students' skills at collaborative knowledge construction to inform future research and instructional practices.

\section{Review of Related Literature}

Two strands of research informed the design of the study: knowledge building and disciplinary literacy. As the goal of this design-based experiment was developing students' abilities to collaboratively direct and sustain effective literature discussions using online tools, a theoretical foundation from cognitive psychology, knowledge building, was selected for its close alignment with the stated goals. Bereiter's Knowledge and Mind for the Knowledge Age (2002), an origin point for knowledge-building learning theories, called for pedagogical practices that encourage knowledge creation to produce students who deeply understand content. Knowledgebuilding learning trains students to generate knowledge through sustained collaboration and problem solving, leading to a shared understanding, or knowledge product. Producing knowledge products can only occur via an essential aspect of knowledge building: progressive discourse that emphasizes improvability of ideas (Bereiter, 2002). Typical classroom literary discussions often feature teacher and students mutually grappling with a problem of interpretation by focusing on textual evidence. These kinds of literary discussions "do not generate progress toward the solution of shared problems of understanding" (Scardamalia \& Bereiter, 2006, p. 102). Teachers may pose open-ended questions and invite students to share their interpretations of an author's craft, but there is one essential aspect missing for progressive literary discourse: the purpose of the discourse is to get somewhere. Thus, progressive literary discourse should result in a final knowledge product: a shared, deep interpretation of a text justified by student analysis and synthesis of literary knowledge.

The second theoretical perspective informing this study, disciplinary literacy, required consideration of the content area or discourse community in which the online discussions took place. Disciplines are distinguished by discourses (Luke, 2001; O'Brien, Moje, \& Stewart, 2001), and recent scholarship in disciplinary literacy recognizes students' need for learning the knowledge of texts and literate practices as well as the inquiry practices/strategies of reasoning 
required in each content area (Goldman et al., 2016; Moje, Young, Readence, \& Moore, 2000). As Moje (2008) noted, "Producing knowledge in a discipline requires fluency in making and interrogating knowledge claims, which in turn require fluency in a wide range of ways of constructing and communicating knowledge" (p. 99). Reading, writing, and discussing literary texts requires cognitive processes, skills, dispositions, and funds of knowledge not engaged when reading other texts (Lee, 2007; Miall \& Kuiken, 1999; Moje et al., 2000; Wineberg, 1991).

Noting the importance of content and rhetorical processes, Goldman et al.'s (2016) conceptual framework for disciplinary literacy captures the unique norms, conventions, and ways of discussing knowledge within a discipline. The authors describe the discourse and reasoning skills students need to interpret literary texts and construct oral and written arguments that communicate their interpretations. For example, expert, literary readers attend to plot and character, language and structure of the text, knowledge of other texts, and awareness of the author's craft, such as the use of symbolism or tone as they affect textual understanding. Literary discussion, like argumentation in the other disciplines, involves supporting claims with evidence, supporting reasoning with credible warrants, and responding to counterclaims (Toulmin, 2003). However, the discourse of literary discussion also accepts personal beliefs and life experience as valid claims. Literary discussion acknowledges texts as a means to understand the nature of human experience, that texts may have ambiguous meanings, and, thus, that multiple interpretations of a text are valid because the discourse and reasoning utilized in literary analysis and discussion accepts the personal beliefs and life experiences of the reader as acceptable warrants (Lee, Goldman, Levine, \& Magliano, 2016). Thus, the present study designed an intervention using online discussion encompassing the aforementioned characteristics of how knowledge is discussed, constructed, challenged, and revised within the literature classroom.

\section{The Intervention and Its Justification}

\section{Improving Online Discourse as a Pedagogical Goal}

Online discussion forums provide a unique opportunity to understand and develop pedagogies that might enable improved collaboration and discussion around content. Researchers believe that asynchronous online discussion forums are potentially ideal environments for the social construction of knowledge (Gao, 2014), providing students and teachers with a space to engage in discourse around content and construct knowledge (Chen, deNoyelles, Patton, \& Zydney, 2017). Online courses that promote high levels of collaboration facilitate increased value in the co-construction of knowledge (Wicks et al., 2015). Nonetheless, online discussions often fall short of this objective (Rourke \& Kanuka, 2009).

Engaging students in online learning requires exploring the nature and the quality of digital interactions that foster connections with other students and the instructors "while developing strong disciplinary knowledge and multidisciplinary skills" (Redmond, Heffernan, Abawi, Brown, \& Henderson, 2018, p. 199). Online learning that nurtures social, cognitive, behavioral, collaborative, and emotional engagement may improve the quality of online learning (Redmond et al., 2018). Moreover, while elements such as learner-to-instructor engagement strategies are highly valued by students (Martin \& Bolliger, 2018), MOOC courses can improve engagement by implementing discussion prompts that foster interactions about deep meaning of concepts covered in the course (Bonafini, Chae, Park, \& Jablokow, 2017). These studies provide a useful framework for improving student engagement in practice and research, but they do not posit specific 
instructional moves. Thus, the present study examines one method for improving student engagement by employing a technique for propelling discussions with structured discourse.

To improve the quality of online discussions, one strand of scholarship has investigated the use of structured discourse. For decades, sentence frames have been employed to facilitate effective face-to-face discussions and collaborative writing (Adler \& Rougle, 2005). Essentially, sentence frames provide language to focus student contributions and advance discussion. Students are presented, for example, with a menu of phrases to begin the first sentence of a discussion, such as, "at first I thought, but now I think," to give them the language that shapes reflective thinking. Also referred to as note starters, these sentence frames are a form of scaffolding intended to deepen student thinking (Nussbaum, Hartley, Sinatra, Reynolds, \& Bendixen, 2004). The first application of note starters in online learning was conducted by Scardamalia and Bereiter (1991) who adopted the practice for online discussions, concluding that the practice supported high-level questions, elaborated explanations, and improved student understanding.

Substantial scholarship in the field of online learning has examined ways to teach students strategies for improving digital discussion. Noting the challenges of online discussions, Hara et al. (2000) designed a study using starters, who initiated weekly discussions around assigned readings, and wrappers, whose task was to summarize the discussions. The authors suggest that defined roles and discussion tasks improved the length, cognitive depth, and discussion posts embedded with peer references. Nussbaum et al. (2004) combined research on argumentation to design a framework for facilitating students' online discussion skills by providing them with note starters to encourage counterargumentation. For example, their note starters included the phrases "my argument is," "I need to understand," and "on the opposite side." The study suggested note starters could be useful for students with low degrees of curiosity and appeared to encourage students to consider other points of view during online discussions. However, the study only studied starters as a method for facilitating student argument; it did not examine the use of note starters as a means for generating ideas around content. Jonassen and Kim (2010) noted the potential of note starters, what they refer to as preclassifying messages to support student learning of the rhetorical structure of argumentation in online forums. Chen and Hun (2002) theorized that if the goal of online learning is to facilitate shared knowledge construction, then note starters, such as those used by Knowledge Forum, are well suited to developing student skills in collaborative discourse. More recently, studies investigating the role of computer-embedded supports, such as note starters, sentence frames, or scaffolds, find them necessary to enhance student learning and collaborative support (Morris et al., 2010; Ng, Cheung, \& Hew, 2010; Noroozi, Weinberger, Biemans, Mulder, \& Chizari, 2013). However, none of the studies cited here examine sentence frames as a tool for developing students' abilities with progressive, literary discourse

\section{Developing Progressive, Literary Discussions With Online Tools as a Pedagogical Goal}

To design an intervention directed toward developing students' abilities to self-direct and sustain online discourse around literary content, it was necessary to investigate the qualities of effective literature discussions established in the research base, paying particular attention to the skills and dispositions educators emphasize. In collaboration with the classroom teacher, I theorized that such teacher-directed discussion practices could be transferred and taught to the students using online digital tools (i.e., sentence frames or note starters) to inform the design of the intervention. Thus, the following review of dialogically organized instruction in the ELA classroom provides insights into the intervention's design. 
For decades, empirical studies in the literacy field have examined the role discussion plays in developing reading, writing, and reasoning appropriate to ELA classrooms (see, for example Applebee et al., 2003; Langer, 1995). The presence of discussion in the literature classroom does not necessarily equate with improved student learning; it is the quality of the discussions that foster reasoning appropriate to literary discussions. Discourse focusing on the student as meaning maker "requires elaboration of the learner's, not the teacher's, interpretive framework" (Nystrand, Gamoran, Kachur, \& Prendergast, 1997, p. 20). Classrooms in which students engage in substantive, ongoing dialogue are characterized by the presence of multiple perspectives, the development and improvement of understandings over time, student questioning, and the practice of building on the comments of other students (Juzwik, Nystrand, Kelly, \& Sherry, 2008; Langer, 1995; Nystrand, Wu, Gamoran, Zeiser, \& Long, 2003). The effectiveness of instructional discourse is "a matter of the quality of teacher-student interactions and the extent to which students are assigned challenging and serious epistemic roles requiring them to think, interpret, and generate new understandings" (Nystrand et al., 1997, p. 7). The most effective ELA dialogue, according to Nystrand et al., required students to think and not merely report someone else's thinking, and this occurred most frequently when teachers asked open-ended questions and challenged students to extend and justify their interpretations.

Thus, I decided to transfer the epistemic roles and teacher-uptake discourse moves established in the literature when designing the intervention. Because the literature establishes the importance of discourse elaborating and building on the learner's interpretive framework, not the teacher's, discussions should begin wherever the students wanted to begin. They should be taught how to start discussion with questions, wonderings, confusions, or anything that they noticed and wanted to discuss. Furthermore, research on effective literary discourse establishes the critical role of teacher uptake, when teachers incorporate student responses to extend and justify students' thinking, into the questions they pose. These are key factors in discussion-based classrooms and are equated with improved literacy skills (Nystrand, 2006; Nystrand, Gamoran, \& Carbonaro, 1998). Thus, if these were the effective teacher moves in rich, dialogically organized instruction, a self-directed and sustained student discourse might mimic these approaches. The intervention should explicitly model and scaffold students' skills and dispositions toward extending, challenging, justifying, and unifying discourse around literature - all discrete uptake moves made by teachers in classrooms identified as dialogically rich environments. Scaffolds and sentence frames built into a digital discussion board, I theorized, could model and reinforce students' application of typical uptake moves.

\section{Employing Knowledge Forum to Achieve Pedagogical Goals}

In studies of knowledge-building classrooms, a computer-supported learning environment, Knowledge Forum, is the principal environment in which work with ideas takes place. It is where ideas are set forth, discussed, revised, organized, and combined (Bereiter \& Scardamalia, 2003). Knowledge Forum is a networked, community knowledge space in which participants contributes notes that may be theories, ideas, questions, references, connections, or multimedia. When contributing a note, participants can co-author, build on, or annotate notes written by other members of the community as well as create keywords "and rise-above notes to summarize, distill, and advance their discussions" (Zhang, Scardamalia, Lamon, Messina, \& Reeve, 2006, p. 123).

Knowledge Forum's ability to structure discipline-specific ways to generate explanatory theories and revise them over time is especially salient to this study. When posting discussion notes, participants must select from a menu of scaffolds to facilitate progressive discourse — similar 
to sentence frames or note starters. For example, when a student wishes to initiate a discussion topic or build on others' ideas, a pop-up window appears, and students must select from a menu of scaffold choices framing their post. These scaffolds initiate the participant's note composition by providing guidance with categories such as "my theory," "I need to understand," "new information," "a better theory," and "putting our knowledge together." Scaffolds are a way to inculcate the structure of discourse in discipline-specific ways. In essence, students internalize the epistemology of the discipline by participating in conversations justified by discipline-appropriate ways of constructing, revising, and thinking about knowledge in the domain.

There is growing support in the literature establishing the effectiveness of Knowledge Forum and knowledge-creating communities for improving student learning in math, science, and social studies (Bielaczyc \& Collins, 2006; Messina \& Reeve, 2006; Moss \& Beatty, 2006; Niu \& Aalst, 2009; Zhang et al., 2006). However, only a few studies investigate knowledge-building learning on literacy skills. Elementary students engaging in knowledge building have shown significant gains in literacy even without any special attention to it (Scardamalia, Bereiter, Burtis, Calhoun, \& Smith Lea, 1992), particularly improvement in discourse, reading, vocabulary growth, and reading to create knowledge (Lamon, Chan, Scardamalia, Burtis, \& Brett, 1993; Scardamalia, 2002; Sun, Zhang, \& Scardamalia, 2010; Zhang \& Sun, 2011). Only one study to date has examined knowledge-building learning in the secondary ELA classroom. Lamon (2005) investigated the use of Knowledge Forum as a tool for improving Grade 9 students' literacy skills, finding a positive correlation between database activity and final grades. However, the unpublished study did not elucidate knowledge-building learning in the ELA classroom beyond suggesting how teachers could generate problems of understanding to drive curricula.

The knowledge building theory of learning, facilitated by Knowledge Forum's ability to train students in mastering a progressive, literary discourse was selected for this study to improve the quality of online discussions. Knowledge Forum's scaffolds focus discussion in a way that classroom discussions cannot; it requires students to build on, advance, challenge, and justify ongoing conversations. The collaborative, knowledge-building nature of the software environment provides ways for participants to see patterns, integrate ideas, and visually map the development of ideas in ways that chats, dialogic journals, classroom discussions, bulletin boards, or threaded discussions cannot. The goal of using Knowledge Forum is to use technology in a way that allows for progressive discourse and the crossing and recrossing of understandings (Spiro, Coulson, Feitovich, \& Anderson, 1994) so that students live an enhanced literary experience with practical application (Scardamalia, 2003). Technology that goes beyond typical discussion formats and can facilitate the use of scaffolds to foster progressive discourse provides both an opportunity to add to the literature concerning online, dialogic, and knowledge-building learning. Moreover, understanding how students learn to apply Knowledge Forum's scaffolds in literary discussions will contribute to the research base regarding sentence frames as a means to improve online discussions.

Research is needed examining how online learning can promote high levels of collaboration leading to the co-construction of knowledge. As online discussions fall short of this objective (Rourke \& Kanuka, 2009), the present study hopes to contribute to the literature on promoting effective, digital discussions particularly in the literacy field. Furthermore, research is needed to provide insights into the cognitive and social practices required for students to manage, understand, apply, and create knowledge (Goldman \& Scardamalia, 2013) in ELA. As design- 
based experiments are interested in how and why a designed intervention works in classroom practice, the research question guiding the present study investigated the following:

- How can digital discussion tools be integrated into conventional ELA instruction to help students learn the reasoning and rhetorical skills and dispositions appropriate to progressive, literary discourse?

\section{Methods}

\section{Research Design}

The present study employed a mixed methods design within the design-based research (DBR) paradigm. Since progressive, literary discourse and its development over time was an essential factor in this research, a methodology had to be selected to track environmental factors and student learning as their discussion, reasoning, and interpretation skills were evolving. The objective of DBR is to understand an emerging theory of educational design, often a close study of a single learning environment, as it passes through multiple iterations to reach a desired goal (Barab, 2006; Gravemeijer \& Cobb, 2006; Parker et al., 2013). Unlike experimental or quasiexperimental research methodologies where data is analyzed at the end of the experiment, designbased research gathers and analyzes data in regular, iterative cycles over the entire course of the experiment, wherein data are analyzed, and suggestions to improve the instructional theory are implemented, followed by a new cycle of data collection and analysis, until the goal is reached (Botha, van der Westhuizen, \& De Swardt, 2005; Collins, Joseph, \& Bielaczyc, 2004; Reinking \& Bradley, 2004). Data were gathered and analyzed as they informed iterative modifications of the intervention guided by questions such as the following: What factors enhance or inhibit progress toward the pedagogical goal? How can the intervention be modified in light of those factors? (Colwell, Hunt-Barron, \& Reinking, 2013; Howell et al., 2017).

\section{The Participants}

As DBR methodology can provide an overwhelming amount of data for daily, weekly, and monthly analysis, it has been recommended to limit the experiment to one class (Reinking \& Bradley, 2008). A call for participants was distributed to schools and teachers within the geographic region situated around a large city in upstate New York. The participants selected for this study, members of a single sixth grade ELA class of 26 students, were chosen for their rich academic and ethnic diversity. Approximately one third of the class was ethnically diverse, and one quarter of the students came from homes where a language other than English was spoken. Additionally, four students of the 26 were identified as requiring instructional support via Individualized Education Plans. To protect the privacy of the teachers and students engaging in this study, signed consent forms from students and their parent were obtained. All data recorded and reported here use pseudonyms to protect participant privacy. In design-based research, the classroom teacher is considered a co-investigator. Thus, data were reviewed and decisions to implement and revise the intervention and delivery of instruction were made with the full participation of the teacher.

\section{The Intervention}

The intervention aligned principles of knowledge-building learning with the regularly prescribed curriculum. No changes were made to what students learned. Rather, design principles 
solely emphasized how students would meet learning objectives. The intervention focused on establishing key components of knowledge-building learning (Scardamalia, 2002):

- Improvable ideas: Learning activities and teacher-student interactions established that all ideas regarding literary theories were improvable and that no knowledge - even that from authoritative sources-was finite.

- Rise above thinking: Learning activities focused on scaffolding students' abilities to develop emerging understandings and encouraging them to build on and extend their own and other students' ideas.

- Progressive discourse: Students practiced adding to, justifying, and challenging literary interpretations in classroom and Knowledge Forum discussions in which the progression of ideas, idea diversity, and building on others' ideas became visible and extended beyond one class or one learning activity.

During the semester-long intervention, key changes were made to weekly instruction. First, Knowledge Forum sessions would take place twice weekly in the school's computer lab to assist students in mastering the software environment's intricacies. Each Knowledge Forum session would be debriefed the following day for the express purpose of providing instructional feedback and guided practice in progressive discourse. For example, a discussion thread that posed interesting questions but was not built on by students would be displayed in class, and the teacher would model ways to add to, justify, challenge, or unify the discussion, and students would practice applying these dialogic skills.

Crafting effective scaffolds, or sentence starters, to focus Knowledge Forum discussion posts toward a progressive, literary discourse was an essential factor affecting the research design. Prior to the intervention reported here, a pilot study applied the theory-building, progressive discourse scaffolds programmed into Knowledge Forum and they were deemed inadequate. Analyses of students' Knowledge Forum discussions during and after the pilot study revealed a high percentage of students initiating discussions but an extremely low percentage of posts that extended and built on other students' posts. It was theorized that this outcome might be a result of Knowledge Forum's discussion scaffolds not being appropriate for knowledge-building, literary discourse. Thus, for the intervention, new discussion scaffolds were designed to mimic the kinds of uptake ELA teachers demonstrate in effective dialogic classrooms (Nystrand, 2006; Nystrand et al., 2003). The old and new scaffolds applied in this intervention are provided in Table 1.

Table 1

Discussion Scaffolds for Knowledge Forum

\begin{tabular}{|l|l|}
\hline $\begin{array}{l}\text { Knowledge Forum's theory-building } \\
\text { discourse scaffolds applied during } \\
\text { pilot study }\end{array}$ & $\begin{array}{l}\text { Literary discourse scaffolds applied } \\
\text { during intervention }\end{array}$ \\
\hline My theory & I want to talk about \\
\hline I need to understand & I have a question \\
\hline This theory cannot explain & Challenging ideas \\
\hline A better theory & Justifying ideas \\
\hline Putting our knowledge together & Extending ideas \\
\hline & The big picture \\
\hline
\end{tabular}


The new scaffolds were designed to assist students in entering and extending online discussions in ways typical of ELA classrooms. The author theorized that these scaffolds would assist students in constructive talk about text as well as highlight the importance of justifying literary interpretations with evidence through the challenging, justifying, and extending scaffolds. Thus, the intervention focused on teaching students progressive discourse that would enable them to create literary knowledge.

As design-based research allows the investigators to tweak the intervention to bring students closer to the educational goal, data were debriefed, by the author and the classroom teacher, in iterative cycles to illuminate the instructional changes affecting learning outcomes. After 10 weeks (Phase 1) it was theorized that changes to the intervention would bring students closer to the research goal. During Phase 2 students were provided sentence starters to help them find the language aligned with specific Knowledge Forum discussion scaffolds (see Appendix A). Students were required to access these sentence starters during all computer sessions and face-toface discussions. Second, in order to propel students to synthesize patterns in the text, as well as making connections to the world beyond the text, a new Knowledge Forum discussion scaffold, the big picture, was introduced and explicit instruction offered to support student mastery of this thinking and discussion technique. These phases and their rationale will be discussed further in the results section.

\section{Student Activity Measures: Knowledge Forum Usage}

To track student growth toward the intervention's pedagogical goal, student mastery of progressive, literary discourse, data were analyzed after each phase of the design-based experiment. Focusing on Knowledge Forum's performance indicators (e.g., use of scaffold supports, discussion tree sizes, notes read, notes built on) provided the primary source of data determining the extent to which students were moving closer to, or away from, the pedagogical goal. Thus, tracking student performance in real time provided necessary data informing the study's research question: How can digital discussion tools be integrated into conventional ELA instruction to help students construct effective, progressive, literary discourse? Teacher interviews, lesson plans, student artifacts, and researcher field notes were used to triangulate quantitative and qualitative analyses in relationship to iterative phases of the design, noting especially instructional changes to the intervention. The learning outcomes presented in the following sections employ quantitative measures from Knowledge Forum and qualitative analyses of student discussions. Interview data, lesson plans, and other artifacts are not discussed explicitly, yet they were used to situate the data within the context of the intervention and student responses as they changed over time.

Quantitative measures were utilized to examine student selection of Knowledge Forum scaffolds to assess the extent to which students were applying the elements of a progressive, knowledge-building discourse appropriate for literary knowledge building. Descriptive statistics of this variable by iterative phase were examined to track the effects of changes to the instructional intervention. Correlational analyses (chi-square) were performed to examine the use of student scaffold supports to aid the understanding of changes to the instructional intervention, across phases, and between Phases 1 and 2. Additionally, Knowledge Forum provides analytic tools to track individual and whole-class discussion contributions. These quantitative measures examining discussion tree sizes and links between student posts were used to understand student application and growth of progressive discourse measures. 
To determine the extent to which students were actually engaged in progressive, literary discourse, discussion trees were analyzed qualitatively, specifically for evidence of students grappling with problems of understanding a text, providing explanatory theories, challenging and verifying such theories, and resolving issues. In essence, progressive discourse requires that student-initiated discussion events should go somewhere, deeper into the text. All threads were analyzed for evidence that students were engaged in solving problems of understanding the text solely through collaboration supported by Knowledge Forum. Threads were also analyzed for evidence of thinking, reasoning, and discussion skills and dispositions appropriate for the literature classroom as discussed in the theoretical and literature review sections of this study. From the perspective of thinking and discussion skills appropriate to literary reasoning, (see for example, Goldman et al., 2016; Lee et al., 2016), discussion threads were examined for students' noticing and noting things on their own, asking questions, being open to multiple interpretations, and either resolving questions, citing several potential answers, or accepting ambiguity.

\section{Results}

Commensurate with recent scholarship in formative and design-based experiments (see, for example, Colwell et al., 2013; Howell et al., 2017), results are presented first as retrospective analysis, evaluating overall student progress made toward accomplishing the pedagogical goal. Afterward, I discuss the enhancing factors and modifications made during the intervention and what the data suggest for modifying the intervention for future iterations.

\section{Knowledge Forum Activity Measures}

To address the research question-How can digital discussion tools be integrated into conventional ELA instruction to help students construct effective, progressive, literary discourse? - students' use of Knowledge Forum scaffold supports and examination of discussion tree size and quantity were examined to determine whether students were applying a progressive, knowledge-building discourse. Table 2 presents an overview from Knowledge Forum's built-in, analytic tools and provides a snapshot of strictly quantitative measures of students' contributions and engagement in progressive discourse.

Table 2

Knowledge Forum Measures

\begin{tabular}{|l|l|l|}
\hline & $\begin{array}{l}\text { Phase 1 } \\
(\mathbf{1 0} \text { weeks) }\end{array}$ & $\begin{array}{l}\text { Phase 2 } \\
\text { (10 weeks) }\end{array}$ \\
\hline Total notes contributed & 240 & 366 \\
\hline Percentage of authors' notes that are linked & $48 \%$ & $65 \%$ \\
\hline Total number of discussion trees & 40 & 80 \\
\hline $\begin{array}{l}\text { Percentage of discussion trees identified as small discussion trees } \\
(2-5 \text { notes })\end{array}$ & $88 \%$ & $85 \%$ \\
\hline $\begin{array}{l}\text { Percentage of discussion trees identified as medium discussion } \\
\text { trees (6-20 notes) }\end{array}$ & $10 \%$ & $14 \%$ \\
\hline $\begin{array}{l}\text { Percentage of discussion trees identified as large discussion trees } \\
(21-40 \text { notes })\end{array}$ & $0 \%$ & $1 \%$ \\
\hline $\begin{array}{l}\text { Percentage of discussion trees identified as very large discussion } \\
\text { trees (more than 40 notes) }\end{array}$ & $2 \%$ & $0 \%$ \\
\hline
\end{tabular}


There are several Knowledge Forum measures that indicate the quantity, if not the quality, of students' participation in progressive discourse. For literary discussion to move forward, to dig deeper into literary analysis, students must show evidence of reading each other's posts and building on them. The category percentage of authors' notes that are linked indicates the percentage of all notes that are connected through building on and extending earlier posts. This statistic increased from $48 \%$ in Phase 1 to $65 \%$ in Phase 2, indicating that the overall, ongoing discourse around literature became less disjointed and more connected.

The snapshot of the size of discussion trees and their corresponding percentages provides another measurement of students' participation in progressive discourse. Discussion trees are threads of related student posts, originating with one note and branching off as students identify and narrow subsequent discussions on particular ideas. As discourse becomes more complex, discussion trees should become longer, and the occurrence of longer discussion trees should become more frequent. There is a fairly consistent pattern here of discussion trees of fewer than five notes. The very large discussion tree from Phase 1 is best understood as an anomaly, as this tree was created by the teacher and was designed to initiate students into online discourse following their reading and study of memoir as a genre. In this light the $1 \%$ of discussion trees categorized as large discussion threads (21-40 notes) during Phase 2 should be seen as positive growth as the thread was entirely student generated. The data presented in Table 2 indicate that over the course of the intervention students grew in their use of progressive discourse in that they read and built on others' posts rather than concurrent posts of students' literary thoughts.

The unique feature of Knowledge Forum is its requirement that students select scaffolds to focus their discussion contributions. To ensure students are learning a progressive discourse, students are required to select from a drop-down menu of choices as they initiate, challenge, justify, revise, or unify their emerging literary understandings. Table 3 describes student selection of scaffold supports between and across experimental phases.

\section{Table 3}

Student Selection of Knowledge Forum Scaffold Supports

\begin{tabular}{|l|l|l|l|}
\hline Scaffold selected & $\begin{array}{l}\text { Phase 1 (10 } \\
\text { weeks) }\end{array}$ & $\begin{array}{l}\text { Phase 2 (10 } \\
\text { weeks) }\end{array}$ & $\begin{array}{l}\text { Total } \\
\text { percentage } \\
\text { across cycles }\end{array}$ \\
\hline Not provided & $23 \%$ & $13 \%$ & $16 \%$ \\
\hline I want to talk about & $35 \%$ & $27 \%$ & $29 \%$ \\
\hline I have a question & $6 \%$ & $9 \%$ & $8 \%$ \\
\hline Challenging ideas & $13 \%$ & $11 \%$ & $11 \%$ \\
\hline Justifying ideas & $3 \%$ & $12 \%$ & $10 \%$ \\
\hline Expanding ideas & $18 \%$ & $24 \%$ & $23 \%$ \\
\hline The big picture & $2 \%$ & $4 \%$ & $3 \%$ \\
\hline & & & $100 \%$ \\
\hline
\end{tabular}

$N=506$ Knowledge Forum discussion posts 
Progressive discourse is essential to knowledge-building learning, and student use of scaffold supports is one way to determine whether students are learning to engage in and apply the conventions of advancing literary discussions toward a knowledge product. Phase 2 showed substantial gains from Phase 1 in student selection of justifying (from 3\% to 12\%) and expanding (from 18\% to 24\%) progressive discourse scaffolds. The decrease during Phase 2 in the use of $I$ want to talk about scaffold (from 35\% to 27\%) evidences students' cohesion and extension of other students' literary interpretations. That is, students demonstrated improvement in building on other students' literary interpretations rather than initiating numerous discussion threads. Across the entire intervention, $37 \%$ of discussion posts were written by students who initiated topics and raised questions about the text, and $44 \%$ of all discussion posts challenged, extended, and justified the formation of textual understanding over time. Students were engaged in rise above thinking by reading each other's posts and extending, justifying, and challenging others' ideas as they read the text.

As there were significant changes to the intervention implemented at the outset of Phase 2, it is important to measure the effects of instructional changes on student outcomes. To determine any influences of the instructional changes between research phases, chi-square tests were conducted to examine whether the proportions of posts in student selection of scaffold supports varied from Phase 1 to Phase 2. The Cramer's $V$ effect size (.204) represents a moderate association for scaffold selected per Rea and Parker's (1992) interpretative guidelines. These results suggest that the proportions of students' Knowledge Forum posts at the different scaffold did in fact differ between Phase 1 and Phase 2 of the study.

Attributing changes to the instructional intervention accounts for some variability in student use of scaffold supports. The twice-weekly debriefings of Knowledge Forum sessions, aligned with the teacher's explicit instruction in mastering a progressive literary discourse, showed improvement of student application of scaffold supports over the entire intervention. However, providing students with sentence starters to shape the kinds of thinking and writing associated with specific progressive discourse moves was the most significant change to the intervention between Phases 1 and 2. During Phase 2, students were required to access and refer to the sentence starters during every Knowledge Forum session as well as during face-to-face classroom discussions. While it is possible to attribute student growth in application of advanced knowledge building, discourse scaffolds to mastery over time, it is more likely that explicit instruction in progressive discourse, aided by the sentence starters, played a significant role in explaining the variability between Phases 1 and 2.

\section{Student Growth Toward Literary Reasoning and Discussion}

The purpose of this design-based experiment was to understand how instructional changes might foster student application of a progressive literary discourse. Data tracking the extent to which students reached the goal of online discussions appropriate to how knowledge is or is not constructed in the ELA discipline provides depth to an understanding of the study's instructional outcomes. All Knowledge Forum discussion trees were examined for the quality of students' progressive literary discourse. As the quantitative findings suggest, students were applying advanced scaffold supports to justify, challenge, and build on other students' posts. However, qualitative analyses investigating the nature of these discussion threads were required to see the extent to which students were engaging in discussion around literature that went somewhere, that resulted in literary interpretations or socially constructed, shared understandings of questions, issues, themes, or concerns noted by readers. Thus, discussion threads were examined for students' 
noticing and noting things on their own, asking questions, being open to multiple interpretations, and either resolving questions, citing several potential answers, or accepting ambiguity as appropriate for literary reasoning (see, for example, Goldman et al., 2016; Lee et al., 2016).

In this section, I present illustrative examples of students' enactment of progressive, literary discourse. These discussion trees are presented not because they are exceptional, but rather because they were typical of the high-quality, progressive discourse students achieved throughout their Knowledge Forum discussions. While there were certainly discussion trees that fizzled out or did not go beyond noticing and noting items or asking questions interesting to the student, those were very few. For clarity and conciseness, both examples encompass discussion of Sharon Draper's young adult novel Out of My Mind (2010).

During Phase 2, student discussion threads evidenced dispositions to literary conventions and applications of reasoning and argumentation indicative of the deepest levels of literary understanding. It took many weeks to establish a culture of idea diversity in which all student ideas are valued and treated as worthy of further discussion, but on this particular day, after several weeks of reading the novel, one student decided the image on the cover held some significance and wanted to bring his theory to the class. Students' Knowledge Forum posts are presented with the scaffold they selected in italics and without mechanical corrections to preserve their original voice:

Azim (I want to talk about): I think that the fish bowl on the cover represents Melodys head. The fish is trapped in the bowl, kind of like how Melodys words are trapped in her head. The fish is constantly swirling around the bowl, kind of like Melodys words swirling around her head. One day when the fish really can't take it anymore, he gets out, and I think that when Melody can't take it anymore, the words will come out. What do you think?

Ashlyn (I have a question): I agree with what you think the cover of the book means. I wonder what will happen if one day melody has a major tornado expoltion and she won't stop?!?!?!?!?!?!

Ashlynn is taking up Azim's theory about what the cover might represent. Azim elaborates on his tentative suggestion, and Ashlyn ponders the implication of Azim's theory and wonders ahead to the remaining, unread portions of the book to see whether his theory might affect her reading predictions.

Lindsey (The big picture): I think that you are correct, but since the fish just decided he cuoldnt take it anymore and jumped out, will melody really explode? And not be able to take it anymore.

Cynthia (Expanding ideas): I agree with you. I also wonder if the fish bowl is a warning for something that might happpen on later in the book. Mabye that something doesn't have to be Melody that has to explodes, mabye it's Mrs.V or Melody's dad or mom. The Dad could explode from all of his stress, or mabey Mrs.V has a dramatic character change, and explodes in one way. Or it might be Mr. Dimming that explodes. Does anybody else think this?

Notice here how Cynthia and Lindsey are picking up Azim's theory and using rise above thinking to add to and suggest alternative theories. This predisposition toward multiple possibilities is indicative of literary reasoning, as the discussants, using tentative language, suggest further 
implications of Azim's reading on predicting the remainder of the plot and character developments.

Azim (Justifying ideas): Wow, you made a great point. I should've thought of that. Maybe it's not Melody that explodes, it could be someone else! Great point Christine

Brian (Expanding ideas): It could be it might also be Melody hase such a big tornato explosions is so bad Melody could have a heart attack from all the strees on her heart ang the fhish that resembols the beat of the heart giving up and jumping out "stopping"

Students were not asked to look for particular literary elements, such as symbols, but as this thread demonstrates, they brought them up on many occasions. Azim wanted to talk about the cover that he felt was important and suggested a theory for what a fish jumping out of the bowl might represent. Ashlyn asks what Azim's theory might mean for predicting future novel events, and Lindsey applies Azim's theory toward a big picture understanding of how the symbol might help her better understand the main character. Cynthia expands and takes up Azim's theory and offers tentative suggestions about the implications of his theory, using language of "maybe" and "it might mean" to expand on the emerging theory of symbolism by suggesting the fish might represent other characters. Brian zeroes in on the language suggested in Azim's follow-up note and suggests the tornado explosions might be a metaphor for heart stoppage.

This thread demonstrates students engaging in progressive, knowledge-building discourse and reasoning specific to the ways literary knowledge is constructed. An interpretation was put forth, students questioned, expanded, and justified the theory, applying constructive argumentation moves to propel the discourse forward, and as they did, a more fleshed-out idea of what the fish symbol might represent was created. This rise above thinking, aligned with constructive literary argumentation, is most likely attributable to the intervention's emphases on idea diversity and knowledge-building discourse, which were explicitly introduced and practiced through Knowledge Forum's discourse scaffolds supported by sentence starters.

Even though students were not explicitly instructed to look for literary elements and author's craft by the teacher, the discussion threads reveal that they noticed them anyway because they seemed important to the students as they were reading. For example, the following discussion took place following the book's completion toward the end of Phase 2:

Malik (I have a question): I wonder why the author ended the book this way. She ended it the same way it begun. Why did she end it with her thinking? Maybe it kind of refreshes back to when Melody couldn't talk, and she could only think, and keep things stuck in her mind. Melody couldn't talk, but now she is capable in a way of verbalizing The author also ended it with a ... so i wonder if there will be a sequel. Melody has been through alot, but I wonder what would've happened if Melody it wasn't from Melodys point of view? What do you think?

Amelia (Justifying ideas): i think she did this to show Melody reflecting back on her self then, what she used to be and what she is now.

Lindsey (Expanding ideas): I think that it would have been a whole diffrent story if it wasnt from melodys point of view because most of the book is her thinking. I also wonder if there will be a sequel. And you said that in the begining she could only think but now she can talk but she said in the end that she is eleven and she has never spoken 1 single word. 
Malik (Expanding ideas): If the Point of view was in Claire or Mollys view, or even Rose, or Dad or Mom, what would they think? Do you have any ideas? The whole story would be a whole new story, what do you think?

Faraj (Expanding ideas): I think that a really interesting point of view would be Mr. Dimming's. I wonder what he would be thinking when he had to leave Melody and when Melody confronted him and the quiz team. How would the author explain his discomfort and how sorry he was?

Iris (Expanding ideas): I agree with Lindsey. I think the story would be way different. It might be similar to Melodys point of view but characters think differently. They see things happen in a different way. I think it would be a whole lot different.

Danielle (I want to talk about): I think it ended the same way it begun because Melodys thinking is the most important part in the story because without her thinking the story would be SOOO different and nobody would understand whats she's going through, and how her life is because if it was from Claires point of veiw, imagine how different that would be! Yes if it wasn't from Melody's point of veiw I specifically wonder what it would be from Rose or Claire because I wonder what Rose was thinking when she didn't call Melody at the airport and also with Claire I wonder what she's thinking when she make's fun of Melody.

Students weighed alternative theories on point of view and how that affected overall textual interpretations. Here, students engaged in synthesizing the elements of author's craft (ending the text identically to the beginning) and point of view to see how these discrete literary elements, if changed, might affect possible, textual interpretations. Students were never told to examine point of view or the novel's structure. They were given the freedom to explore topics and questions they generated, and they raised these issues because they noticed that they might be important. This kind of literary talk, analyzing and synthesizing literary elements into a cohesive interpretation is indicative of progressive, literary discourse. In other discussion threads, students brought up theme, symbolism, irony, and characterization, carefully weighing evidence to support multiple interpretations.

There were no significant patterns or differences in the qualitative analyses of the discussion threads between Phases 1 and 2. Again, because students were applying Knowledge Forum's progressive, literary discourse scaffolds to their digital conversations from the very beginning, the qualitative analyses of discussion threads across phases demonstrate consistent student application of constructive argumentation, literary reasoning, and progressive discourse throughout the intervention. While there were discussion threads that did not progress deeper into the text — or fizzled out over time - they were in the minority.

\section{Enhancing Factors and Modifications}

In this section, I describe two enhancing factors that influenced the formative modifications to the intervention, bringing the students closer to the pedagogical goal. As the study's research question investigated how digital tools can be integrated into conventional ELA instruction to help students to construct effective, literary discourse, I discuss two instructional modifications that springboarded student growth between and across phases.

Synchronous debriefings of asynchronous discussion. During Phase 1 of the study, data analyses revealed that while students were initiating discussions and asking questions, there was 
inadequate use of the advanced scaffolds that would guide students to dig deeper into the text, more fully articulating their interpretations, and challenge, justify and extend emerging literary theories. Thus, it was decided to implement a significant change to the intervention for Phase 2: increasing the frequency (from weekly to biweekly) of the debriefings of Knowledge Forum discussions. During these sessions, discussion threads were projected on the classroom screen, and students were given explicit instruction in ways to apply specific discourse scaffolds - especially challenging ideas, extending ideas, and the big picture - in an attempt to move discourse further along. These face-to-face learning activities presented models from the previous day's discussion posts of effective student use of extending, justifying, or challenging peer's posts with appropriate reasoning and constructive discourse. The teacher would lead discussion on how and why a discussion thread moved ideas deeper into the text and evidenced appropriate literary reasoning. Additionally, a student discussion thread that did not advance beyond a question or brief response was presented to the entire class, and a specific discussion scaffold, such as challenging ideas, was modelled by the teacher. Students practiced writing build-on posts applying this scaffold until they could apply these discourse moves independently. In short, instructional scaffolding of how, when, and why to use specific discourse moves was taught until student work evidenced mastery.

Discussion scaffolds and sentence frames equated with literary reasoning and argumentation. Language shapes thinking. Prior to the implementation of the intervention, Mrs. Fleck, the classroom teacher, lamented the lack of student discussion that went deeper into the texts. "My students," she noted, "will answer questions about plot or character, or when asked to make a connection or prediction will share something, but there's no building upon others' thoughts or listening to each other." Over the course of the intervention, students grew in their selection and application of extended discussion scaffolds, such as challenging and justifying ideas, and the online discussion threads presented here demonstrate students applying the literary reasoning and discussion skills to sustain in-depth literary talk using digital tools. I attribute these findings to Knowledge Forum's potential to identify, explicitly model, and scaffold cognitive processes associated with progressive, literary discourse.

In Phase 2 we applied the common practice of providing sentence starters or frames for face-to-face or written discussions to digital discourse (see Appendix A). Students were required to employ these with every computer session and classroom discussion. As the data indicate, there were quantitative improvements in the students' deep literary understanding during Phase 2, and chi-square analyses support the conclusion that instructional changes made between Phases 1 and 2 had a measurable effect. The sentence starters enabled students to internalize the language to shape the thinking that deepened discussions in a constructive and collaborative manner.

\section{Future Modifications}

Despite introducing the big picture scaffold and thinking during Phase 2 of the intervention, there was little evidence of students selecting and applying this scaffold during Knowledge Forum discussions. The intent of the big picture scaffold is to propel student discussions to look beyond the text and make connections to other texts, personal experience, or ways the text helps them understand themselves or the world around them. Additionally, the big picture scaffold was intended to help students look for connections between online discussion threads covering different topics and seek ways to bring about coherence of ideas. For example, Knowledge Forum debriefing sessions attempted to provide instructional scaffolding teaching students how to bring various discussion thread topics (e.g., plot, characterization, and symbolism) together, analyzing and synthesizing them into an overall interpretation of the text. The goal was 
to help students develop literary interpretations over time, to observe how their interpretations were developing by looking back at previous discussion threads. There was no evidence of students looking backward and synthesizing ideas from previous discussion threads.

As clarifying understanding over time is a cognitive reasoning process associated with strong readers, future modifications to the intervention might examine ways to explicitly model and guide students to make connections across discussion threads. Literary analysis is equated with synthesizing elements, such as plot and characterization, with authorial moves, such as linguistic devices, symbolism, and tone, into a coherent, overall interpretation of text. Future modifications might examine ways to propel students to use digital tools to mimic this kind of literary reasoning and argumentation. It may be as simple as teaching students to use digital tools to identify keywords and link discussion threads by topic or ideas. This might better contribute to student awareness and application of discussions that bring about coherence of differing threads.

\section{Discussion}

Asynchronous, online discussion forums are potentially ideal for the social construction of knowledge, yet these often fall short of this objective. This study took up the challenge of adapting online learning environments, such as Knowledge Forum, to instruct students in the discussion and thinking appropriate for advancing knowledge in the literature classroom. The goal of this designbased experiment was to develop a theory of instruction, grounded in the real world of the classroom that addressed how using online discussion forums might enhance students' ability to learn progressive, knowledge-building discourse in ways appropriate to the ELA discipline. If effective, it would also satisfy the need to train students in 21 st-century learning practice and skills.

Empirical studies within the literacy research field have established a connection between dialogically organized instruction and improved student textual comprehension. A knowledge-building approach to literature instruction - to borrow a concept from Nystrand (1997) - ups the ante for conceptualizing what dialogically organized instruction might teach through its emphasis on progressive discourse. Describing effective dialogic episodes correlated with high levels of students literary understanding, Nystrand et al. (1997) noted the importance of teacher uptake moves that "restate" and "orchestrate" moving discussion forward. They up the ante by probing and pushing students to expand, modify, justify, clarify, and confirm their thoughts and orchestrate and focus whole class response. The data presented here suggest that teaching students to notice and note textual elements on their own and socially construct textual interpretations engaging in progressive, online discourse scaffolded by Knowledge Forum, helps students learn to up the ante themselves by applying the disciplinary literary reasoning associated with how knowledge is constructed, argued, and advanced in the ELA classroom.

This capacity to up the ante is attributable to Knowledge Forum's potential to identify, explicitly model, and scaffold cognitive processes associated with progressive, literary discourse. In the effective dialogic classroom, teachers up the ante by asking students to rethink, justify, add information, and challenge the interpretations of others. In the case of this design-based experiment, I theorized that Knowledge Forum's theory-building discourse scaffolds could be replaced with scaffolds mimicking teacher discussion moves equated with deep comprehension of texts. Students demonstrated that they could apply the ways that English teachers typically uptake student responses during classroom discussion. In the present study, students mirrored the moves teachers normally make in guiding classroom discussions and made them on their own, enhancing the quality of constructive and collaborative progressive discourse. This was brought about by programming teacher uptake 
moves into the Knowledge Forum scaffolds. Thus, because students were required to select a scaffold focusing their discussion contribution, they learned to internalize and apply effective, literary discourse norms. The literary scaffolds I want to talk about, I have a question, challenging ideas, extending ideas, justifying ideas, and the big picture played an essential role in the study's positive outcomes.

These literary discourse scaffolds also supported student mastery of the unique ways knowledge is constructed when discussing literature. In the literature classroom, we want students to form interpretations, extend them by identifying macrotextual patterns, engage in inferential thinking, and state analyses supported by evidence. The literary scaffolds made the nature of literature discussion explicit and reinforced student internalization of ways of thinking associated with strong readers. In an era in which educational researchers and practitioners seek to make teaching and learning more active and participatory, this study demonstrated that students could engage in deep discussion of text without teacher direction. More than applying constructivist approaches to learning, students were creating knowledge precisely because they learned the ways to talk about and build understanding of a text, rather than taking in teacher observations about a text's meaning.

A reasonable conclusion from the data presented here is that students demonstrated application of progressive, literary discourse and knowledge construction because the scaffolds programmed into Knowledge Forum facilitated student learning of these higher order reasoning skills. Proponents of dialogically organized instruction have suggested that practitioners adopt ways to frame students' thoughts via explicit instruction in the ways of initiating and entering into classroom discussions about text, typically supported by giving them sentence starters, the language with which to initiate what they want to say (Adler \& Rougle, 2005; Langer, 2011). The daily practice in class, the constant requirement to select a scaffold appropriate for posting an original note or building on the ideas of others, helped students internalize the structure and shape of literary thought and discourse. Student discussions on Knowledge Forum did not fizzle out or result in excessive "good idea" or "interesting" comments that imply value but ultimately go nowhere, as is often the case in digitally mediated dialogue. These students were moving literary understanding deeper because the scaffolds they chose required them to do so.

\section{Limitations and Implications}

This design-based experiment produced a theory of instruction tracing the achievement of an educational objective and the modifications to learning activities and the classroom environment that brought students closer to the stated goal. Correlation or causation cannot be established; an experimental or quasi-experimental study should be the next step in measuring the efficacy of the instructional methods established in this study on developing progressive, online discourse. Because lasting effects of interventions on student learning require time, it makes sense that further research should be at least one year in duration rather than the one semester in this study. Future research investigating the efficacy of progressive, literary discourse on ELA curricula needs to encompass a variety of school contexts, grade levels, and content.

By turning over responsibility for understanding texts entirely to the students by using an online environment, and by teaching them how to engage in extended, collaborative knowledge building around literary interpretations, we have the potential to understand much more about how to improve the teaching of ELA curricula and the central role online discussion forums may play in enabling students to create deep understanding of content. 


\section{References}

Adler, M., \& Rougle, E. (2005). Building literacy through classroom discussion: Research-based strategies for developing critical readers and thoughtful writers in middle school. New York: Scholastic.

Applebee, A. N., Langer, J. A., Nystrand, M., \& Gamoran, A. (2003). Discussion-based approaches to developing understanding: Classroom instruction and student performance in middle and high school English. American Educational Research Journal, 40(3), 685-730. https://doi.org/10.3102/00028312040003685

Barab, S. (2006). Design-based research: A methodological toolkit for the learning scientist. In K. Sawyer (Ed.), The Cambridge handbook of the learning sciences (pp. 153-169). New York: Cambridge University Press.

Bereiter, C. (2002). Knowledge and mind in the knowledge age. Mahwah, NJ: Erlbaum.

Bereiter, C., \& Scardamalia, M. (2003). Learning to work creatively with knowledge. In E. De Corte, L. Verschaffel, N. Entwistle, \& J. van Merrienboer (Eds.), Powerful learning environments: Unraveling basic components and dimensions (pp. 55-68). Oxford, UK: Elsevier Science.

Bielaczyc, K., \& Collins, A. (2006). Technology as a catalyst for fostering knowledge-creating communities. In A. M. O’Donnell, C. E. Hmelo-Silver, \& G. Erkens (Eds.), Collaborative learning, reasoning, and technology (pp. 37-60). Mahwah, NJ: Lawrence Erlbaum Associates.

Bonafini, F. C., Chae, C., Park, E., \& Jablokow, K. W. (2017). How much does student engagement with videos and forums in a MOOC affect their achievement? Online Learning, 21(4). doi:10.24059/olj.v21i4.1270

Botha, J., van der Westhuizen, D., \& De Swardt, E. (2005). Towards appropriate methodologies to research interactive learning: Using a design experiment to assess a learning programme for complex thinking. International Journal of Education \& Development Using Information \& Communication Technology, 1(2), 105-117.

Carnegie Council on Advancing Adolescent Literacy. (2010). Time to act: An agenda for advancing adolescent literacy for college and career success. New York: Carnegie Corporation of New York.

Chen, B., deNoyelles, A., Patton, K., \& Zydney, J. (2017). Creating a community of inquiry in largeenrollment online courses: An exploratory study on the effect of protocols within online discussions. Online Learning, 21(1), 165-188. http://dx.doi.org/10.24059/olj.v21i1.816

Chen, D. T., \& Hung, D. (2002). Personalised knowledge representations: The missing half of online discussions. British Journal of Educational Technology, 33(3), 279.

Collins, A., Joseph, D., \& Bielaczyc, K. (2004). Design research: Theoretical and methodological issues. Journal of the Learning Sciences, 13(1), 15-42.

Colwell, J., Hunt-Barron, S., \& Reinking, D. (2013). Obstacles to developing digital literacy on the Internet in middle-school science instruction. Journal of Literacy Research, 45, 295-324. doi:10.1177/1086296X13493273

Common Core State Standards Initiative. (2010). English language arts standards; Reading: Literature; Grades 9-12. Retrieved from http://www.corestandards.org/ELA-Literacy/RL/9-10/

Draper, S. (2010). Out of my mind. New York: Atheneum Books for Young Readers. 
Ford, C., McNally, D., \& Ford, K. (2017). Using design-based research in higher education innovation. Online Learning, 21(3). doi:10.24059/olj.v21i3.1232

Gao, F. (2014). Exploring the use of discussion strategies and labels in asynchronous online discussion. Online Learning, 18(3). doi:10.24059/olj.v18i3.460

Goldman, S. R., Britt, M. A., Brown, W., Cribb, G., George, M., Greenleaf, C., . . Project, R. (2016). Disciplinary literacies and learning to read for understanding: A conceptual framework for disciplinary literacy. Educational Psychologist, 51(2), 219-246. doi:10.1080/00461520.2016.1168741

Goldman, S. R., \& Scardamalia, M. (2013). Managing, understanding, applying, and creating knowledge in the Information Age: Next-generation challenges and opportunities. Cognition and Instruction, 31(2), 255-269. doi:10.1080/10824669.2013.773217

Gravemeijer, K., \& Cobb, P. (2006). Design research from a learning design perspective. In J. van den Akker, K. Gravemeijer, S. McKenney \& N. Nieween (Eds.), Educational design research (pp. 17-51). New York: Routledge.

Hara, N., Bonk, C. J., \& Angeli, C. (2000). Content analysis of online discussion in an applied educational psychology course. Instructional Science, 28(2), 115-152.

Howell, E., Butler, T., \& Reinking, D. (2017). Integrating multimodal arguments into high school writing instruction. Journal of Literacy Research, 49(2), 181-209. doi:10.1177/1086296X17700456

Jonassen, D. H., \& Kim, B. (2010). Arguing to learn and learning to argue: Design justifications and guidelines. Educational Technology Research and Development, 58(4), 439-457.

Juzwik, M. M., Nystrand, M., Kelly, S., \& Sherry, M. B. (2008). Oral narrative genres as dialogic resources for classroom literature study: A contextualized case study of conversational narrative discussion. American Educational Research Journal, 45(4), 1111-1154. doi: $10.3102 / 0002831208321444$

Lamon, M. (2005). Information and communications technology and literacy development. Paper presented at the Proceedings of CSCL 2005: The Fifth International Conference on Computer Support for Collaborative Learning, Taipei, Taiwan.

Lamon, M., Chan, C., Scardamalia, M., Burtis, P. J., \& Brett, C. (1993). Beliefs about learning and constructive processes in reading: Effects of a computer supported intentional learning environment (CSILE). Paper presented at the annual meeting of the American Educational Research Association, Atlanta, GA.

Langer, J. A. (1995). Envisioning literature: Literary understanding and literature instruction. New York: Teachers College Press.

Langer, J. A. (2011). Envisioning knowledge: Building literacy in the academic disciplines. New York: Teachers College Press.

Lee, C. D. (2007). Culture, literacy, and learning: Taking bloom in the midst of the whirlwind. New York: Teachers College Press.

Lee, C. D., Goldman, S. R., Levine, S., \& Magliano, J. (2016). Epistemic cognition in literary reasoning. In W. Sandoval, I. Braten, \& J. Green (Eds.), The handbook of epistemic cognition (pp. 165-183). New York: Routledge.

Luke, A. (2001). Foreword. In E. B. Moje \& D. O'Brien (Eds.), Constructions of literacy: Studies of teaching and learning in and out of secondary classrooms (pp. ix-xii). NJ: Erlbaum. 
Martin, F., \& Bolliger, D. U. (2018). Engagement matters: Student perceptions on the importance of engagement strategies in the online learning environment. Online Learning, 22(1). doi:10.24059/olj.v22i1.1092

Messina, R., \& Reeve, R. (2006). Knowledge building in elementary science. In K. Leithwood, P. McAdie, N. Bascia, \& A. Rodrigue (Eds.), Teaching for deep understanding: What every educator should know (pp. 110-115). Thousand Oaks, CA: Corwin Press.

Miall, D. S., \& Kuiken, D. (1999). What is literariness? Three components of literary reading. Discourse Processes, 28(2), 121-138. doi:10.1080/01638539909545076

Moje, E. B. (2008). Foregrounding the disciplines in secondary literacy teaching and learning: A call for change. Journal of Adolescent \& Adult Literacy, 52(2), 96-107. doi:10.2307/20111747

Moje, E. B., Young, J. P., Readence, J. E., \& Moore, D. W. (2000). Reinventing adolescent literacy for new times: Perennial and millennial issues. Journal of Adolescent \& Adult Literacy, 43(5), 400 410.

Morris, R., Hadwin, A. F., Gress, C. L. Z., Miller, M., Fior, M., Church, H., \& Winne, P. H. (2010). Designing roles, scripts, and prompts to support CSCL in gStudy. Computers in Human Behavior, 26(5), 815-824. doi:10.1016/J.CHB.2008.12.001

Moss, J., \& Beatty, R. (2006). Knowledge building in mathematics: Supporting collaborative learning in pattern problems. Computer-Supported Collaborative Learning, 1(December), 441-465. doi:10.1007/s11412-006-9003-z

Ng, C. S. L., Cheung, W. S., \& Hew, K. F. (2010). Solving ill-structured problems in asynchronous online discussions: Built-in scaffolds vs. no scaffolds. Interactive Learning Environments, 18(2), 115-134. doi:10.1080/10494820802337629

Niu, H., \& van Aalst, J. (2009). Participation in knowledge-building discourse: An analysis of online discussions in mainstream and honours Social Studies courses. Canadian Journal of Learning \& Technology, 35(1). http://dx.doi.org/10.21432/T2M88C

Noroozi, O., Weinberger, A., Biemans, H. J. A., Mulder, M., \& Chizari, M. (2013). Facilitating argumentative knowledge construction through a transactive discussion script in CSC. Computers \& Education, 61, 59-76. doi:10.1016/J.COMPEDU.2012.08.013

Nussbaum, E. M., Hartley, K., Sinatra, G. M., Reynolds, R. E., \& Bendixen, L. D. (2004). Personality interactions and scaffolding in on-line discussions. Journal of Educational Computing Research, $30(1 / 2), 113-137$.

Nystrand, M. (2006). Research on the role of classroom discourse as it affects reading comprehension. Research in the Teaching of English, 40(4), 392-412.

Nystrand, M., Gamoran, A., \& Carbonaro, W. (1998). Towards an ecology of learning: The case of classroom discourse and its effects on writing in high school English and social studies Albany: National Research Center on English Learning and Achievment, University at Albany.

Nystrand, M., Gamoran, A., Kachur, R., \& Prendergast, C. (1997). Opening dialogue: Understanding the dynamics of language and learning in the English classroom. New York: Teachers College Press.

Nystrand, M., Wu, L. L., Gamoran, A., Zeiser, S., \& Long, D. A. (2003). Questions in time: Investigating the structure and dynamics of unfolding classroom discourse. Discourse Processes, 35(2), 135198. 
O’Brien, D., Moje, E. B., \& Stewart, M. A. (2001). Exploring the context of secondary literacy: Literacy in people's everyday school lives. In E. B. Moje \& D. O'Brien (Eds.), Constructions of literacy: Studies of teaching and learning in and out of secondary classrooms (pp. 27-48). NJ: Erlbaum.

Parker, W. C., Lo, J., Yeo, A. J., Valencia, S. W., Nguyen, D., Abbott, R. D., . . Vye, N. J. (2013). Beyond breadth-speed test: Toward deeper knowing and engagement in an advanced placement course. American Educational Research Journal, 50(6), 1424-1459.

Partnership for 21 st Century Skills. (2008). 21st century skills, education \& competitiveness: A resource and policy guide. Retrieved from http://www.21stcenturyskills.org/documents/21st_century_skills_education_and_comptetitivenes s guide.pdf

Rea, L. M., \& Parker, R. A. (1992). Designing and conducting survey research. San Francisco, CA: Jossey-Bass.

Redmond, P., Heffernan, A., Abawi, L., Brown, A., \& Henderson, R. (2018). An online engagement framework for higher education. Online Learning, 22(1). doi:10.24059/olj.v22i1.1175

Reinking, D., \& Bradley, B. A. (2004). Connecting research and practice using formative and design experiments. In M. K. Duke \& M. H. Mallette (Eds.), Literacy research methodologies (pp. 149169). New York: The Guilford Press.

Reinking, D., \& Bradley, B. A. (2008). On formative and design experiments: Approaches to language and literacy research (an NCRLL volume). New York: Teachers College Press.

Rourke, L., \& Kanuka, H. (2009). Learning in communities of inquiry: A review of the literature. Journal of Distance Education, 23(1), 19-48.

Scardamalia, M. (2002). Collective cognitive responsibility for the advancement of knowledge. In B. Smith (Ed.), Liberal education in a knowledge society (pp. 67-98). Chicago, IL: Open Court.

Scardamalia, M. (2003). Crossing the digital divide: Literacy as by-product of knowledge building. Journal of Distance Education, 17(Suppl. 3), 78-81.

Scardamalia, M., \& Bereiter, C. (1991). Higher levels of agency for children in knowledge building: A challenge for the design of new knowledge media. The Journal of the Learning Sciences, 1(1), $37-68$.

Scardamalia, M., \& Bereiter, C. (2006). Knowledge building: Theory, pedagogy, and technology. In K. Sawyer (Ed.), The Cambridge handbook of the learning sciences (pp. 97-115). New York: Cambridge University Press.

Scardamalia, M., Bereiter, C., Burtis, P. J., Calhoun, C., \& Smith Lea, N. (1992). Educational applications of a networked communal database. Interactive Learning Environments, 2(1), 45-71.

Spiro, R. J., Coulson, R. L., Feitovich, P. J., \& Anderson, D. K. (1994). Cognitive flexibility theory: Advanced knowledge acquisition in ill-structured domains. In R. B. Rudell, M. R. Rudell, \& H. Singer (Eds.), Theoretical models and processes of reading (4th ed.). Newark, DE: International Reading Association.

Sun, Y., Zhang, J., \& Scardamalia, M. (2010). Knowledge building and vocabulary growth over two years, Grades 3 and 4. Instructional Science, 38(2), 147-171. doi:10.1007/s11251-008-9082-5

Toulmin, S. E. (2003). The uses of argument (2nd ed.). New York: Cambridge University Press.

Wicks, D., Craft, B. B., Lee, D., Lumpe, A., Henrikson, R., Baliram, N., . . Wicks, K. (2015). An evaluation of low versus high-collaboration in online learning. Online Learning, 19(4). doi:10.24059/olj.v19i4.552 
Wineberg, S. S. (1991). On the reading of historical texts: Notes on the breach between school and the academy. American Educational Research Journal, 28(3), 495-519. doi:10.3102/00028312028003495

Zhang, J., Scardamalia, M., Lamon, M., Messina, R., \& Reeve, R. (2006). Socio-cognitive dynamics of knowledge building in the work of 9- and 10-year-olds. Educational Technology Research and Development, 55(2), 117-145. doi:10.1007/s11423-006-9019-0

Zhang, J., \& Sun, Y. (2011). Reading for idea advancement in a grade 4 knowledge building community. Instructional Science, 39(4), 429-452. 


\section{Appendix A}

\section{Table A1}

Sentence Starters for Literary Knowledge Building

\begin{tabular}{|c|c|}
\hline Knowledge Forum scaffold & Sentence starters \\
\hline I want to talk about & $\begin{array}{l}\text { I want to talk about ... } \\
\text { I noticed ... } \\
\text { As I was reading I noticed ... } \\
\text { After reading/discussion I noticed ... }\end{array}$ \\
\hline I have a question & $\begin{array}{l}\text { What still confuses me is ... } \\
\text { I don't understand ... } \\
\text { I wonder why ... } \\
\text { What if . . } \\
\text { Why is it that ... }\end{array}$ \\
\hline Challenging ideas & $\begin{array}{l}\text { I have a different idea ... } \\
\text { I'm not sure I understand. Could you show me something in the } \\
\text { text that makes you say that? } \\
\text { I disagree with you because ... } \\
\text { Everyone seems to think } \\
\text { What in the text makes you believe that? }\end{array}$ \\
\hline Justifying ideas & $\begin{array}{l}\text { This makes sense to me because ... } \\
\text { I agree with you because ... } \\
\text { While I realize __ ; I think__ because . . }\end{array}$ \\
\hline Expanding ideas & $\begin{array}{l}\text { This reminds me of ... } \\
\text { At first I thought } \ldots \text {; now I think ... } \\
\text { A part of the text that makes me believe this is ... }\end{array}$ \\
\hline The big picture & $\begin{array}{l}\text { Maybe this book is about ... } \\
\text { I think it means } \quad \text { because ... } \\
\text { In the end I believe ... } \\
\text { My conclusion at this point is that . }\end{array}$ \\
\hline
\end{tabular}

